\section{References}

1. Streeten EA, Murphy EA, Pyeritz RE. Pulmonary function in the Marfan syndrome. Chest. 1987;91:408-12.

2. Epstein SK, Ciubotaru RL, Wong JB. Effect of failed extubation on the outcome of mechanical ventilation. Chest. 1997;112:186-92.

3. Tokuda Y, Matsumoto M, Sugita T, et al. Bilateral diaphragmatic paralysis after aortic surgery with topical hypothermia: ventilatory assistance by means of nasal mask bilevel positive pressure. $J$ Thorac Cardiovasc Surg. 2003;125:1158-9.

4. Ferrer M, Esquinas A, Arancibia F, et al. Noninvasive ventilation during persistent weaning failure: a randomized controlled trial. Am J Respir Crit Care Med. 2003;168:70-6.

5. Esteban A, Frutos-Vivar F, Ferguson ND, et al. Noninvasive positivepressure ventilation for respiratory failure after extubation. $N$ Engl J Med. 2004;350:2452-60.

\title{
Embryologic and surgical considerations in tetralogy of Fallot with right arch and aberrant left subclavian artery from the ascending aorta
}

\author{
K. G. Shyam Krishnan, MCh, Sanjay Theodore, MS, Sai Kiran K. V. S. S., \\ MCh, and Kurur Sankaran Neelakandhan, MCh, Kerala, India
}

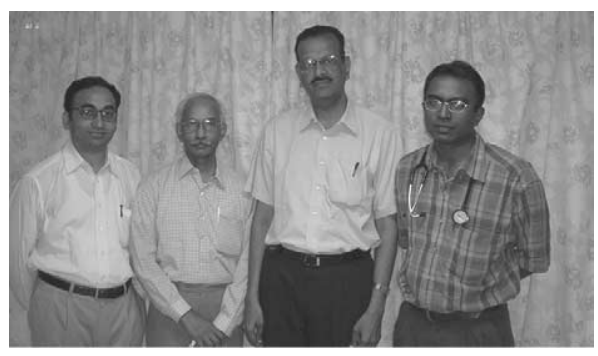

Left to right: Sai Kiran, Neelakandhan, Shyam Krishnan, Theodore
A nomalies of the right aortic arch are common in tetralogy of Fallot (TOF). Aberrant left subclavian artery (LSA) from the Kommerell diverticulum and isolation of the LSA are occasionally encountered. LSA arising as the first branch of a right aortic arch has been reported $^{1}$; however, this is the first report of aberrant LSA arising from the ascending aorta in TOF with a right aortic arch.

\section{Clinical Summaries}

PATIENT 1. A 12-year-old boy had a history of cyanosis since 3 months of age. TOF was diagnosed when he was 3 months old, and he was lost to follow-up. On examination all peripheral pulses were palpable, and blood pressure was $110 / 70 \mathrm{~mm} \mathrm{Hg}$ in both the upper limbs. Both heart sounds were heard, and there was a grade $3 / 6$ ejection systolic murmur over the second left intercostal space. Preoperative blood chemistry, hematology, and coagulation profile showed normal results. Chest radiography and electrocardiogram were consistent with TOF. Transthoracic echocardiography showed a right aortic arch, large subaortic ventricular septal defect with aorta-mitral continuity, and severe infundibular hypertrophy. The pulmonary annulus was small, and the branch pulmonary

From the Department of Cardiovascular and Thoracic Surgery, Sree Chitra Tirunal Institute for Medical Sciences and Technology, Trivandrum, Kerala, India.

Received for publication Oct 20, 2004; accepted for publication Nov 1, 2004.

Address for reprints: Professor Shyam Krishnan KG, Department of Cardiovascular and Thoracic Surgery, Sree Chitra Tirunal Institute for Medical Sciences and Technology, Trivandrum, Kerala, India 695011.

J Thorac Cardiovasc Surg 2005;130:215-6

$0022-5223 / \$ 30.00$

Copyright $\odot 2005$ by The American Association for Thoracic Surgery

doi:10.1016/j.jtcvs.2004.11.004 arteries were of a good size. At surgery an abnormal LSA arising from the ascending aorta anterolaterally was found, coursing anterior to the trachea and the esophagus. This vessel was looped and snugged before delivery of cardioplegic solution. The patient had an uneventful postoperative course and is on regular follow-up.

PATIENT 2. TOF was diagnosed at the age of 3 months in patient 2 when the parents noticed cyanosis. The patient's heart rate was 130 beats/min and blood pressure was $90 / 60 \mathrm{~mm} \mathrm{Hg}$ in both the upper limbs. Chest radiograph and electrocardiogram were consistent with TOF. Transthoracic echocardiography showed a right aortic arch, a large subaortic ventricular septal defect with a 50\% aortic override, a hypertrophied right ventricle, and confluent and adequate-sized pulmonary arteries. Coronary anatomy was not well defined, so a cardiac catheterization and angiography were performed. The ascending aortic angiogram showed an aberrant LSA arising from the posterolateral ascending aorta and passing anterior to the trachea and esophagus (Figure 1). The patient underwent successful corrective surgery. During surgery, the aortic clamp was applied proximal to the aberrant vessel.

\section{Discussion}

A right aortic arch occurs in approximately $25 \%$ of patients with TOF with pulmonary stenosis. The right arch shows 3 branching patterns: mirror image branching, aberrant LSA, and the rare isolation of the LSA. The aberrant subclavian artery arises from the descending aorta. To date there are no reports in the English literature describing the origin of the LSA from the ascending aorta in TOF with right aortic arch. ${ }^{1}$

The branching configuration of the right aortic arch largely depends on the pattern of left arch regression. In the commonly found mirror image branching, the distal portion of the left arch regresses, the proximal portion incorporates with the subclavian artery, and the innominate forms on the left. The aberrant LSA is formed from the left dorsal aorta, left fourth arch, and left seventh intersegmental artery. ${ }^{2}$ 

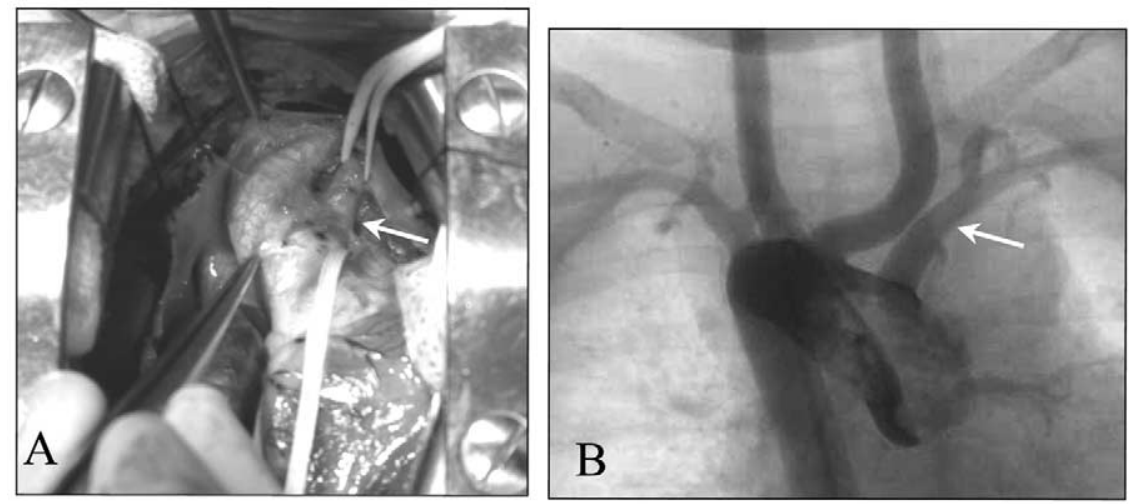

Figure 1. A, Aberrant subclavian artery from the ascending aorta looped. B, Aberrant left subclavian artery (LSA) arising from the ascending aorta.

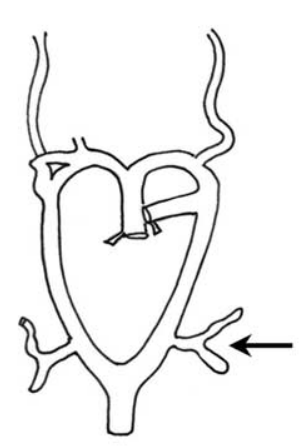

A

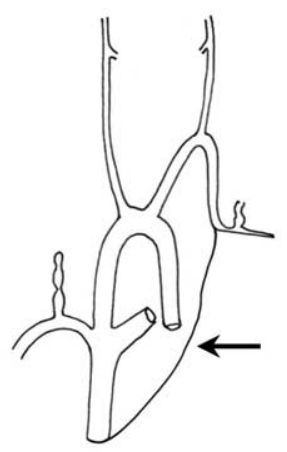

B

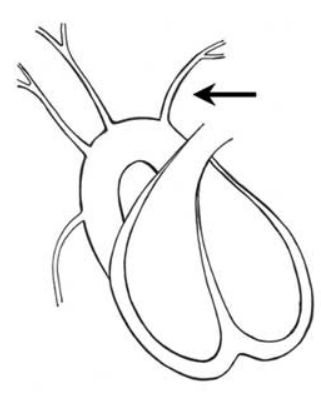

C

Figure 2. A, Paired dorsal aorta showing the position of the seventh intersegmental artery before cephalad migration. B, Cephalad migration with regression of the left dorsal aorta. C, Incomplete cephalad migration resulting in LSA arising from the ascending aorta.

Boechat and associates ${ }^{3}$ described 2 patients in whom the LSA arose as the first branch of the arch. They believed that in case of common origin of the carotids, the subclavian may arise separate$1 y^{3}$ however, in our patients the carotids had an independent origin from the arch (Figure 1). Moes and Freedom ${ }^{4}$ believe that a separate origin of subclavian artery may occur as the result of persistence of the left fifth aortic arch and incorporation of the ipsilateral seventh intersegmental artery. In the 5- to 6-mm embryo, the arteries of the sixth and seventh intersomite pairs arise from the paired dorsal aorta. The final position of the subclavian artery is determined by their cephalad migration. ${ }^{5}$ We believe the arrest of the cephalad migration may result in nonfusion of the left third and fourth arches resulting in an aberrant subclavian artery arising from the ascending aorta (Figure 2).

This aberrant vascular pattern may have no clinical significance because there is no vascular ring; however, this assumes great importance when there is an associated congenital heart disease such as TOF. If recognized preoperatively, the arterial line should preferably be on the right radial or femoral arteries. The vessel should be dissected and looped preoperatively. If the aortic cross- clamp is applied distal to its origin, before delivery of cardioplegic solution, the vessel should be "snugged" to prevent cardioplegia runoff and inadequate myocardial protection.

We believe that an aberrant subclavian artery arising from the ascending aorta is a rare anomaly and may have an embryologic association in TOF with a right arch. This clinically insignificant vessel assumes great importance for adequate myocardial protection during cardiac operations.

\section{References}

1. Knight L, Edwards JE. Right aortic arch-types and associated cardiac anomalies. Circulation. 1974;50:1047-51.

2. Baron MG. Right aortic arch. Circulation. 1971;44:1137-45.

3. Boechat MI, Gilsanz V, Fellows KE. Subclavian artery as the first branch of the aortic arch: a normal variant in two patients. Am J Roentgenol. 131:721-2.

4. Moes CFA, Freedom RM. Rare types of aortic arch anomalies. Pediatr Cardiol. 1993;14:93-101.

5. Goor DA, Lillehei CW. Embryology of the heart in congenital malformation of the heart. New York: Grune and Stratton; 1975:79-90. 